\title{
Dynamics and Trends in Vaccine Procurement and Distribution in Zimbabwe
}

\author{
John P. Maketo ${ }^{1 *}$, Bismark Mutizwa ${ }^{2}$ \\ ${ }^{1}$ Social and Behavioural Sciences, University of Zimbabwe. Zimbabwe. \\ ${ }^{2}$ Public Administration, University of Zimbabwe. Zimbabwe.
}

Article History
Received:
04.10 .2021

Revised:
29.10 .2021

Accepted:
08.11 .2021
*Corresponding Author:
John P. Maketo
Email:
jpmaketo@gmail.co

This is an open access article, licensed under: $C C-B Y-S A$
Abstract: The subject of COVID-19 vaccines has generated debate across the globe as it has created a fecund ground for a plethora of dynamics such as vaccine diplomacy, misinformation, and struggle for dominance among global powers to mention but a few. Thus, the vaccine subject has takencenter stage in global discourses, resulting in developing and developed nations experiencing challenges in respect to purchase, transparency, and accountability in the administration of vaccines. The subject of vaccines in Zimbabwe has provoked public skepticism indicative of the existing trust deficit between government and the citizens. This emanates from strong evidence of abuse of public resources and hence questions of transparency and accountability especially in relation to disaster situations. To this end, this paper seeks to bring to light the trends and dynamics in vaccine procurement and distribution in Zimbabwe. The study examines the correlation between vaccine diplomacy (donation-trap diplomacy) and vaccine purchases. A chronological analysis of the approved vaccines, rejection of Johnson and Johnson and sudden acceptance, natural resource implications of the donations from ALROSA, poor public resource management, vaccine shortages, vaccine misinformation and vaccine cheating. Possible ways of enhancing vaccine intake through quality information are also discussed and Zimbabwe's performance against other African nations is examined. The research ends by proposing a series of questions which should be embraced to fully comprehend the trends and dynamics of vaccine procurement and distribution.

Keywords: COVID-19, Donation Trap, Economies of Affection, Vaccine Diplomacy. 


\section{Introduction}

This study seeks to discuss the dynamics and trends of vaccine procurement and distribution in Zimbabwe. Informed by desktop research, interviews with key informants from the Ministry of Health and Child Care, National COVID-19 taskforce, relevant civil society organisations and key informants spread across districts in Zimbabwe, the study establishes the issues of concern surrounding COVID-19 vaccines in Zimbabwe. To further an explorative discussion, the research lays out several for further reflection and probe with respect to COVID-19 vaccines and public resource management. The intention is to promote a culture of transparency and accountability through factual rigorous debate thereby adding extensively to the body of knowledge

\section{Background}

As of 11 August 2021, one year four months have passed since the World Health Organisation (WHO) declared COVID-19 a global pandemic and one year seven months since the emergence of COVID-19 in China on the 31st of December 2019. Since then, the COVID-19 pandemic has ravaged the world resulting in unprecedented recession far greater than anything global economies have experienced since the great depression and World War 2 [1]. Developed, developing and resource constrained states are all deploying necessary interventions to curtail the spread of the virus with the global North taking a lead. One of the key measures for responding to the pandemic has been the development and use of vaccines. The subject of vaccines has been shrouded in controversy with some African countries believing that it is a hoax to swindle Africans of their resources [2]. Despites numerous submissions on COVID-19 vaccines (both negative and positive), countries across the globe have all embraced vaccines as one of the practical ways to permanently curb and mitigate the pandemic [3]. As part of the global community, Zimbabwe has also embraced vaccines as a solution to COVID-19. Currently, Zimbabwe has approved 5 COVID-19 Vaccines which attained (EUA) Emergence Use Authorisation and approval from WHO. These are Sinopharm (China), Sinovac (China), Sputnik V (Russia), Covaxin (India) and the Johnson \& Johnson [4]. However, just like most government - led initiatives in Zimbabwe, the issue of COVID-19 vaccines is shrouded in secrecy and controversy due to limited transparency, integrity, accountability, and equitable vaccine dissemination.

On the 31 st of January 2021 the government announced that it had set aside US\$100 million for the procurement of 20 million vaccines targeting approximately 10 million people which is $60 \%$ of the population to achieve herd immunity [5]. The government noted that the funds were not borrowed but taken from the 2020 budget surplus [5]. Since then, the government has failed to sufficiently and progressively publicize the amount used. Concerning are donations that are coming from China because Zimbabwe and China have been engaged in opaque mega-deals that have culminated in resource backed loans [6].

The increase in vaccine donations from the China and Russia coupled with previous opaque megadeals that the government has been engaged in with the duo makes citizens skeptical about vaccine donations. Citizens are left with many questions about the nature of these donations. They seek to understand the cost at which Zimbabwe is getting the vaccine donations and determine if there are no broader national resource implications. Hence the need for broad research that interrogates the dynamics and trends surrounding vaccine procurement and distribution.

\section{Situational Context}

The COVID-19 third wave is hovering around the globe and Zimbabwe has already detected the B.1.617.2 variant (Delta variant) associated with the third wave [7]. The Vice President and Minister of Health issued an official statement acknowledging that the B.I.617.2 variant was now in Zimbabwe. The B.1.617.2 was first discovered in India and is responsible for most cases in pockets of England, Kenya and South Africa. It is one of the three subtypes of the virus identified in Zimbabwe and is thought to be lethal and highly contagious. The third wave is emerging at a time when Zimbabwe was enjoying considerable gains with respect to COVID-19 mitigation. The country was enjoying a good national recovery rate which has however dropped from $94 \%$ as of 30 May 2021[8] to $62 \%$ as of 14 July 2021[9]. This speaks to the scale and magnitude of the threat that the third wave poses to the national response to COVID-19 and ultimately national growth and development.

Amidst growing threats of the COVID-19 third wave, reports have emerged across the country pertaining to the shortages [10] of COVID-19 vaccines. On the 26th of May hospitals and clinics in Bulawayo were only inoculating people seeking their second dose due to vaccine shortages. This was 
confirmed by the Provincial Medical Director Welcome Mlilo who noted that this was due to an increase in the numbers of people who were seeking to be vaccinated [11]. The National Coordinator for government's response to COVID-19, Doctor Agnes Mahomva reinforced the assertion by the Provincial Medical Director for Bulawayo by noting that Harare and Bulawayo were among the cities who had issues with vaccine shortages. Nonetheless this was due to the slow pace of the vaccine rollout process by the Ministry and not due to shortages [12]. Contrary to what the National Coordinator of Government's Response to COVID-19 said, small towns were also experiencing vaccine shortages as evidenced by the fact that they were only inoculating those who had come for the second dose; this was confirmed at Chiredzi and Chipinge General Hospitals.

Ironically, these shortages of vaccines were happening at a time when the government was rejecting its allocation of the Johnson and Johnson vaccine under the African Union (AU) COVID-19 Vaccine Programme [13]. In its justification, the government of Zimbabwe highlighted its lack of capacity to maintain the required temperature for the vaccine as its major reason for rejecting the donation. This illuminates the service, managerial and operational incapacities of the government's vaccine rollout strategy. If Zimbabwe had taken the Johnson and Johnson vaccine on time, it would have gone a long way in reducing the shortages that was being experienced. Since the Johnson and Johnson vaccine requires just one jab for full inoculation, the allocation from the AU would have gone a long way in meeting the country's targets. The Johnson and Johnson (J\&J) vaccine was developed by Janssen Vaccine in Leiden, Netherlands and it's Belgian parent company who are both subsidiaries of Johnson and Johnson a company from the United States of America (USA). Thus, the rejection of the J\&J at first is thought to have been in line with the government's Look East stance as it considers the Russians and Chinese friendlier than the Americans. The decision which might be understood ostensibly under the prism of international geopolitics a dynamic that should never underestimated in pandemic management.

Despite the shortages of vaccines being experienced, Zimbabwe introduced the vaccine tourism program whereby foreigners can come to Zimbabwe and get vaccinated at a cost [14]. Nonetheless, this could have huge implications to the Zimbabwean community as many foreigners might flock to Zimbabwe and use their financial endowment to be vaccinated at the expense of Zimbabweans who are facing a shortage already. This is a threat to government's a fiduciary role to protect its citizens first. The modern government (developed or developing) is premised on the social contract between citizens and the state in which rights and duties are agreed to by all to further the common interest. Thus, citizens offer their support to a government through taxes and efforts to a country's good; in return, governments attain legitimacy by protecting the people's rights through public policies and social protection policies that are inclusive.

Therefore, given this narrative the vaccine tourism project will entrench social and economic injustice as it will entrench inequality by segregating Zimbabweans based on their financial incapacitation

\section{Conceptual Framework}

The analysis was conducted under the prism of the concept of dynamics. The concept of dynamics is derived from physics, it denotes a state where there is unpredictable and constant change. The concept of dynamics best explains the complex COVID-19 governance system that advances numerous interests which to a greater extent are tailor-made to promote self-interest of different players. Intersecting dynamics such as vaccine diplomacy, donation-trap, broader national resource implications, geopolitics, pricing, and efficacy rate will help in understanding the structural realism that advances the zero-sum and game theory as it involves countries such as China, Russia and India competing to donate and sell their vaccines to Zimbabwe. At the core of the conceptual framework is the need to seek an understanding of the following questions: Which COVID-19 Vaccines is Zimbabwe using and what influenced her choice? What explains the sudden change in the approval of the $\mathrm{J} \& \mathrm{~J}$ ? Where has Zimbabwe purchased its vaccines from and at what cost? Where have COVID-19 vaccine donations to Zimbabwe come from and at what cost? Is there a correlation between vaccine donations and purchases? Who benefited the most - donor or the recipient? What has been the trend of vaccine distribution and uptake in Zimbabwe? What are the causes of vaccine cheating, avoidance and manifestation of corruption in vaccine rollout programme? Lastly but not least what are the broader national resource implications in the vaccine discourse? 


\section{Result and Analysis}

\subsection{Global Perspective on COVID-19 Vaccines Dynamics and Vaccine Diplomacy}

COVID-19 vaccine dynamics on a global arena has manifested under the prism of economies of affection, structural realism (geopolitics) and vaccine diplomacy. The concept of economies of affection asserts that one's proximity to power determines what he or she gets and how policies can be manipulated to her or his favor. The same speaks also to vaccine diplomacy. Thus COVID-19 vaccines dynamics and political economy of the same is substantiated by how rich countries' interests are advanced over those of poor countries. Vaccine purchasing priority is given to rich nations despite an international agreement to allocate vaccines equitably around the world [15]. Doucleff citing researchers at Duke University noted that, at this rate "billions of people in poor and middle-income countries might not be immunized until 2023 or even 2024" [16]. This is necessitated by the financial muscle and limited vaccine production capacity of rich countries; rich countries in this scenario refers to first world nations. Doucleff [16] propounded that:

"As of October2020, wealthy countries have claimed the vast majority of that capacity, leaving very little vaccine for low-income countries. Specifically rich countries have already purchased, or are in the process of purchasing more than 5 billion doses of candidate vaccines before clinical trials have completed. India has claimed another 1.6 billion doses and Brazil has 200 million. Fewer than 800 million doses have been earmarked for the world's poorest countries"

The vaccine political economy is further advanced by the rejection of other nations' vaccine. This is evidenced by the fact that Russia was the first nation to authorize vaccines when the Sputnik vaccine came out. USA, UK and other western nations rejected offers from the Russian government for free vaccines despite not having alternative vaccines at the time [17]. The rejection of Russia s vaccines was purely based on their self-interest which takes precedence in the international community. The same was done to the Sinopharm and Sinovac vaccines from China. In return China and Russia are alleged to have initiated a vaccine misinformation diplomacy and this was revealed by the EU External Action Service Report 2021 [18] which noted that China and Russia were engaged in a media blitz against the west.

As the struggle for power and hegemony over developing nations by China, Russia, USA, UK and European countries continues China is projecting itself as the savior, redeemer and solution to the pandemic rather than the origin of the coronavirus. China has initiated advanced vaccine diplomacy which contrasts with the "me first policy" of the USA and European Union [19]. China has rolled out vaccines to its Belt and Road Initiative (BRI) participants increasing its hegemony and dominance in their governance structures and decision making. This has been sustained by media gimmick to boost perceptions of China as a generous and responsible power. It is critical to note that China's global alliances have all received vaccine donations. Zimbabwe is a case study as she has received 500000 doses as of 25 June 2021.

Vaccine diplomacy has brought to light fundamental truths such as "hybrid cold war" which is underway between China and Western powers. Hybrid-cold war is defined as a "mix of diplomatic, economic, cyber and information-related actions, all of which fall below the threshold of armed conflict but are, nonetheless, disruptive to the workings of the international system" [17]. In a move that projects underlining dynamics of the international system, China advanced its vaccine political economy by easing restrictions on travel into China for international travelers if they provide proof of vaccination from either Sinopharm or Sinovac [17]. Thus, forcing all those who intend to travel to China to purchase Chinese vaccines.

\subsection{Unpacking Dynamics and Trends in Vaccine Procurement and Distribution in Zimbabwe}

This section shall present the dynamics and trends in vaccine procurement and distribution in Zimbabwe. These dynamics and trends intersect either to advance effective pandemic management or deter it. To give a chronological analysis of the dynamics, intricacies and trends in vaccine procurement and distribution this paper shall start by presenting countries that have donated vaccines to Zimbabwe in order to establish the positive correlation between vaccine purchases, vaccine rejection, vaccines approval, natural resources implications, poor public resource management, vaccine shortages, vaccine misinformation, vaccine cheating and avoidance as well as Zimbabwe's performance against other African nations. 


\subsubsection{Countries That Have Donated Vaccines to Zimbabwe}

As of 12 August 2021, Zimbabwe had received approximately 660, 000 doses of donations from China, Russia and India. The vaccines include 500000 Sinopharm [20] doses, 75000 Sputnik doses [21], 50000 Sputnik doses from ALROSA Group [22] and 35000 Covaxin doses from India. Nonetheless, according to one key informant in the National COVID-19 taskforce, only 50000 Sputnik doses (ALROSA) were delivered, and nothing has been made public about the 75000 doses. This is contrary to the information released by the Minister of Information on the 26th of February when she noted that Zimbabwe will soon receive 75000 doses of the Sputnik V from Russia. Given the discrepancy of the information released by the Minister of Information and the one provided by the key informant there, it is evident that there are information gaps within the system designed to manage the acquisition and distribution of COVID-19 vaccines. It is possible for the public to be furnished with wrong information at any instance. Below is table 1 with the quantity of donated vaccines, their value as well as efficacy rate. The table also covers the 75000 doses from Russia although they have not been received.

Table 1. Vaccines Donated to Zimbabwe as of July 2021

\begin{tabular}{lcccrrr}
\hline Country & $\begin{array}{c}\text { Vaccine } \\
\text { Type }\end{array}$ & Cost & Efficacy Rate & $\begin{array}{c}\text { Donated } \\
\text { Vaccines }\end{array}$ & \multicolumn{1}{c}{$\begin{array}{c}\text { Value of } \\
\text { Donation }\end{array}$} \\
\hline Russia & Sputnik & US\$ 10 & $91.6 \%$ & 125000 & US\$ & $1,250,000$ \\
\hline China & Sinopharm & US\$ 5 & $79 \%$ & 500000 & US\$ $2,500,000$ \\
\hline India & Covaxin & US\$20 & $81 \%$ & 35000 & US\$ & 700,000 \\
\hline Total & & & & 660000 & US\$ $4,450,000$ \\
\cline { 2 - 6 }
\end{tabular}

Source: Primary Data Compiled by Authors from sources

Although, the donations signify a good gesture and the principle of humane treatment there is need to interrogate and ascertain whether it was just a simple gesture of solidarity and generosity or a diplomatic snare to force Zimbabwe into purchasing its vaccines from the donor countries. While these questions keep boggling the minds of the citizens the following subsection: 5.2.2; seeks to do justice to the question by trying to unravel the dynamics surrounding vaccine donations.

\subsubsection{Is It an Act of Generosity or Donation-Trap Diplomacy?}

Although Zimbabwe has received a considerable number of vaccine donations, it is critical to note that most citizens are skeptical about the donations. This is because the government previously has been engaged in opaque-mega deals with the Chinese and Russians that are not only unsustainable but have left Zimbabweans vulnerable and impoverished [23]. This can be evidenced by Resource Backed Loans (RBLs) which Zimbabwe has contracted from these countries without the citizens' knowledge. ZIMCODD (2021) [6] citing Mutondoro et al (2020) noted that:

"Some conservative figures shows that Zimbabwe has contracted approximately US\$ 6.8 billion as RBL from China over the past two decades. However due to the lack of contract transparency and opaque nature of some these RBLs, their real magnitude and extend is difficult to ascertain and the US\$ 6.8 billion could be an under-estimation of reality."

The nature of opaque deals and the magnitude of RBLs tempts one to believe that the donations might have attached conditions, or the donations might be a form of gratitude from the developed countries for exploring Zimbabwe's natural resources. Therefore, it is against this backdrop that citizens are worried that the donations might be little hand-outs that Zimbabwe is receiving from developed countries at a higher cost than what is being communicated to the public. News24 (2021) noted that China and Russia are the ones who approached Zimbabwe offering to donate and supply vaccines as they knew Zimbabwe's financial predicament. The duo had business leaders who offered to pay for vaccine donations to Zimbabwe [24]. This approach was made possible because Zimbabwe is in debt distress and has no capacity to purchase adequate vaccines or borrow from reputable international institutions such as the WB because of country risk, bad debtor, and restrictive measures. According to the 2021 National Budget Statement, Zimbabwe is saddled with domestic debt hovering at around ZWL\$12.5 billion, and external debt estimated at US\$8.2 billion as of 30 September 2020. 
The national debt stock (public and publicly guaranteed) is estimated to be $78.8 \%$ of the country's Gross Domestic Product which is above the 70\% threshold stipulated in the Public Debt Management Act and above the SADC threshold of $60 \%$.

To this end, there is a possibility that the donations might have been informed by the need to have a diplomatic and strategic move to ensnare Zimbabwe into purchasing vaccines from the donating nations. As there is an observed correlation between vaccine donations and purchases, vaccine donations from China were followed by purchases of vaccines from China. News24 (2021) noted that China and Russia approached Zimbabwe offering to donate and supply vaccines [25]. The fact that China and Russia are the ones who approached Zimbabwe projects procurement anomalies and manipulation as it violated all the principles of public procurement which are meant to safeguard public funds. The public procurement procedures that were violated in the process include but are not limited to: accountability, transparency, competitive supply value for money, integrity, consistency, informed decision-making as well as legality and fair dealing. Effective public procurement is one that is premised on transparency, competitiveness, and value for money. It is tailor-made to safeguard and advance the interests of the citizens by initiating robust feasibility studies that inform public purchases which are calibrated to respond to public outcry [26].

However, the donations might have been done in good faith with the need to help Zimbabweans as their government had no financial muscle to respond swiftly to the pandemic. Even so, the stipulated public procurement principles consider the donations as a form of bribe or kickback. This is because China and Russia stand to win more in the procurement deal than Zimbabwe. This can be reinforced by the fact that the government of Zimbabwe announced that it was purchasing 1.2 million doses from China (Sinopharm vaccine) soon after it had received donations. The vaccines which Zimbabwe purchased from China far surpass the donations it received. The total cost of Chinese donations is US\$ 2, 500, 000 (500 000 doses) while the cost of purchases is US\$18, 500,000 (3.7 million doses). Therefore, it is just for one to argue that donations were used as a gimmick and form of enticement to make Zimbabwe feel more compelled to purchase vaccines from China as a return of her good will.

In addition, China has stirred debate among scholars due to her hunger and appetite to extend her hegemony. Although it is debatable, there is a greater possibility that just like the debt-trap diplomacy, China is using donation-trap diplomacy to make third world countries feel obliged to purchase their vaccines from China. Henceforth, the advancement of Chinese interests through donations which brings in the undeniable manifestation of political economy in COVID-19 vaccines.

The concept of donation-trap diplomacy is further reinforced by a purchase of 1 million Covaxin vaccines from India which are yet to be delivered to Zimbabwe. Each Covaxin vaccine dose costs approximately US\$20. Zimbabwe received 35000 doses of vaccines as a donation which cost approximately US\$700,000. The value of the donated doses is less than the value of the purchased vaccines as evidenced by the 1 million doses purchase made by Zimbabwe to India. The estimated value of the purchase is approximately US\$20 million. It is without a doubt that donation-trap diplomacy has disregarded value for money audit which is the nerve-center of prudent fiscal management. There are other vaccines with lower prices and efficacy rates than that of Covaxin; for example, the Sinopharm vaccine comes at a cost of US\$5 while the Covaxin cost is at US\$20. Other vaccines with better prices and efficacy rates as compared to the Covaxin include but are not limited to Johnson and Johnson US\$10 (72\%), Sputnik US\$10 (91\%), Novavax US\$16 (90.98\%), Bharat Biotech US\$2 (78\%), Abdala and Soberan (Cuba 92\%) and finally the AstraZenec-Oxford which comes with different prices for different regions: US\$2.15 (US) and US\$3-4 (EU) and for Africa US\$5.25 (70\%) [27].

In the same vein the health and infrastructural gaps in the Zimbabwean Health Sector also pose another major determinant in vaccine purchases. Zimbabwe does not have the prerequisite storage facilities for vaccines which require minus 70 degrees or even 20 degrees temperatures. This means that even the vaccine logistics for supply and resupply need to be recalibrated to suit the required vaccine temperature. It is also important to note that there are other vaccines which cost less than the Covaxin and for which Zimbabwe has the infrastructural capacity to handle such as the AstraZenecOxford (UK), Novavax (USA) and the Bharat (India). These vaccines require temperatures of 2-8 degrees Celsius for storage which the country can handle. Therefore, given this scenario it can be argued that the decision to disregard certain vaccines is not due to incapacity to provide storage and might have been influenced by "donation-trap diplomacy" or global geopolitics which have been at the core of Zimbabwe`s decision making for the past two decades when she decided to look east. 


\subsubsection{Approved COVID-19 Vaccines in Zimbabwe}

Currently, the Zimbabwean government has only approved the use of five vaccines namely Sinopharm and Sinovac from China, Covaxin from India, Sputnik V from Russia and J\&J from the USA. This is despite the fact that there are other vaccines which have better efficacy rates and more competitive prices than the current approved vaccines. Although it is debatable, there is a correlation between the approved vaccines and donations-trap diplomacy as four of the approved vaccines had been donated first. The decision to approve majority of vaccines which had been donated first should not be treated as coincidence but rather a clear manifestation of geopolitics. However, one key informant from the COVID-19 National Taskforce argued that, "the reason for the selection of the Russian, Chinese and Indian vaccines had less to do with geopolitics but rather the storage facilities and the storage temperatures which other vaccines require". A good example is that of the Mordena and Pfizer-BioNTech vaccines which require extremely cold storage temperatures. Pfizer-BioNTech vaccines need to be kept at an extreme temperature of minus 70 degrees Celsius which is colder than winter in Antarctica while the Mordena vaccine needs to be frozen at minus 20 degrees Celsius which is a regular freezer. The key informant noted that Zimbabwe does not currently have adequate health infrastructure to receive, store and distribute the Pfizer-BioNTech and Mordena vaccines.

Although the narrative by the key informant was sound, the response was not satisfactory as citizens remained skeptical and questioned government's rationale in taking long in approving the $\mathrm{J} \& \mathrm{~J}$ vaccine which requires normal refrigeration temperature. Since January, the government only approved the J\&J vaccine in July. A decision which can be argued to have been ostensibly influenced by pressure from vaccine shortages and other global players as she had no empirical sufficient reason in turning down $J \& J$ vaccines. The geopolitics and foreign policy inclination in the approval of vaccines in Zimbabwe is further exacerbated by the government's failure to approve other vaccines which have favorable temperatures and prices such as AstraZenec-Oxford (UK), Novavax (USA) and the Bharat (India). These vaccines require a cold chain temperature infrastructure of 2-8 degree Celsius and Zimbabwe already has it in place. A good example is that of the AstraZenec-Oxford which is being used in South Africa and has proven to be effective.

\subsubsection{The Rejection of Johnson and Johnson Vaccines and Sudden Acceptance}

The dynamics and trends in vaccine procurement continue to manifest through the intersection of politics and economy. On the 2nd of June 2021, the government of Zimbabwe turned down 3 million doses of J\&J vaccines which it had been allocated under the African Union COVID-19 Vaccination Programme. The rejection of $\mathrm{J} \& \mathrm{~J}$ vaccines happened at a time when the country was experiencing vaccine shortages. In their argument for rejection of the said vaccines, the government cited cold chain infrastructural incapacity to handle the J\&J vaccine. However, the argument was not valid because the $\mathrm{J} \& \mathrm{~J}$ vaccine requires storage temperatures of 2-8 degrees Celsius and Zimbabwe already has those cold chain mechanisms to store vaccines at the required temperature. One wonders whether, the rejection of $\mathrm{J} \& \mathrm{~J}$ vaccines might have been propelled by geopolitics and foreign policy inclination as Zimbabwe is an ally of China and Russia following her fall-out with Western nations in 2000.

The government's decision raised a lot of questions among citizens, academia and CSOs. Some of the questions include but not limited to the following; what are the future implications on international support in the event of other disasters, will Zimbabwe be eligible for support after this gesture? With Zimbabwe seeking to rebuild its international image and re-engagement drive, was it a prudent move to deny the AU arranged vaccine donations? It was such questions coupled with the undeniable advantages of $J \& J$ vaccines over other vaccines that made the government change its decision. This is because, the decision to reject $J \& J$ vaccines defied logic and value for money audits which is the nerve-center of public resource management since the $\mathrm{J} \& \mathrm{~J}$ vaccines is administered as a one-dose as compared to Sinopharm and Sinovac which requires two doses. Thus, the cost of rolling out J\&J is much less than that of rolling out Sinovac, Sinopharm, Covaxin and Sputnik. Therefore, in terms of economic values and public finance management principles it was expedient for the country to accept the $\mathrm{J} \& \mathrm{~J}$ vaccines and even consider it for purchase given its one-dose advantage which outweighs the two-dose requirement of the four vaccines approved in Zimbabwe.

\subsubsection{The Natural Resource Implications of ALROSA Donations}

The vaccine question can never be detached from the national resource discourses especially with the emergence of the COVID-19 third wave which threatens the gains made by the government in the first and second wave. The third wave is regarded as more lethal and has already caused panic across 
the nation with vaccine shortages emanating. At the same time the Zimbabwean government has no access to international lines of credit such as World Bank and IMF. IMF recently ruled out a Zimbabwe bailout package despite having cleared its debts in 2016 [28]. This puts Zimbabwe in a desperate position with regards to vaccine purchasing, leaving her to leverage on her own resources for lines of credits. However, it is imperative to note that issues related to RBL are highly classified and are a privilege of the minority.

To this end, the donations by ALROSA have raised many questions with respect to natural resources management. ALROSA is the leader of the world diamond mining industry, a Russian partially state-owned diamond mining company, it operates in 10 countries and 3 continents. One of the key questions being, are 50000 doses of Sputnik more valuable than the mining concessions which ALROSA is taking over or is it just an act of corporate social responsibility? The opaque nature of the arrangement between the Zimbabwean government and ALROSA makes the whole scenario complicated. In 2019 ALROSA and the Zimbabwe Consolidated Diamond Company (ZCDC) entered a joint-venture in which ALROSA controls 70\% stake while ZCDC controls 30\% stake [29]. In the joint-venture ALROSA has 25 prospecting concessions in Matebeleland North and South as well as Masvingo. It is also targeting diamond prospects previously held by DTZ-Ozgeo from Russia which are in Chimanimani. ALROSA intends to increase its prospective concession from 25 to 40 . Thus, the way ALROSA is taking over the Zimbabwean mining industry brings reminiscence of the days of the "Rudd Concession" which ignited colonial domination in the country through exclusive mining rights.

In addition, it remains unknown to the citizens whether ALROSA was given a tax holiday in return or not. This is because the tax incentives regime in Zimbabwe is fragmented and shrouded in secrecy. Nonetheless, if it has not already been given a tax holiday, then ALROSA's gesture should not be treated as an act of kindness but an enticing move to force the Zimbabwean government into giving tax holidays to the company. It is interesting to note that the donation of 50,000 doses of the Sputnik vaccine cost US\$500, 000 (plus shipping costs depending on whether these were footed by the company or the government of Zimbabwe). It therefore defeats logic to celebrate a US $\$ 500,000$ donation when ALROSA is exploiting local mining communities and using unsustainable mining practices. The minerals being explored have a greater value than the US\$500, 000 worth in donations. Therefore, there is need for citizen scrutiny into the deals and operations of ALROSA lest another US $\$ 15$ billion or more sophisticated scandal is looming.

Although this study notes that the donations by ALROSA can be best understood under the prism of the structural realism dynamics which is premised on zero-sum and game theory. The theory notes that one nation wins at the expense of the other and hegemonic dominance is at the core of every decision, be it donation or act made by nations in the international community. This view is validated by Omoyefa (2008) [30] who noted that there is no free lunch in Paris town. Omoyefa was trying to say that African nations should not just expect free gifts as there is nothing like that; 'gifts' from developed nations come at a price. Thus he moved forward to call for a philosophical rethinking of African public administration.

\subsubsection{Poor Public Resource Management}

Rent-seeking and economies of affection in the purchase of COVID-19 vaccines have made it almost impossible to uphold the principle of good public resource management such as transparency, accountability, and responsibility. The Procurement Regulatory Authority of Zimbabwe (PRAZ) which is at the apex of public procurement has been completely rendered powerless as they were not furnished with tenders for vaccine purchases and supply. This is against its mandate as it was established to "supervise public procurement proceedings to ensure transparency, fairness, honesty, cost-effectiveness and competition as required by section 315 of the Zimbabwean constitution" [31]. The complete disregard of a meta-governance institution meant to infuse robust public management is a clear testimony to how self-interest and politically exposed persons undermine resource management in Zimbabwe. In addition, the government has also failed to exercise its duty of ensuring transparency in vaccine acquisitions for its citizens. In January 2021 the government indicated that they had set aside US\$100 million for vaccines and the money was being taken from the 2020 budget surplus. In July 2021 the government further announced that it had used US\$93 million of the US\$100 million meaning that only 4.7 million doses have been purchased which is $26.8 \%$ of the targeted 20 million doses. The fact that US\$93 million failed to purchase even a quarter of the intended vaccines brought public skepticism with regards to government's sincerity in providing the much-needed 
vaccine in the face of the pandemic. Thus, it would be prudent if the government can provide granular (detailed) data for vaccine purchases.

In addition, the 2020 Auditor General's report on COVID-19 funds exposed weak internal control mechanisms as approximately US\$ 89022103 meant for vulnerable Zimbabweans heavily affected by COVID-19 was looted [32]. The money was for cushioning the elderly, people with disabilities, small-to-medium enterprises whose operations have been affected by lockdowns, child-headed households, food insecure households and chronically ill persons. The report noted that, the US\$89 million could not be accounted for because of:

"The processes of identification and assessment of intended beneficiaries was not properly coordinated, resulting in unreliable databases of beneficiaries, processing of payments to duplicate beneficiary names and beneficiaries who had similar identity numbers, but of different gender and dates of birth".

However, abuse of public resources by public officials is not a new phenomenon in Zimbabwe year-in- year out the Office of the Auditor General continues to earth astonish abuse of public finances but no one has been brought to book. Nevertheless, what is more worrying about the vaccine purchasing discourse is the silence by the Parliamentary Portfolio Committee for Health and Child Care which in terms of section 299 of the constitution of which outlines its oversight role in the utilization of public resources. The questions remain on whether the silence concurs with the notion of political economy of COVID-19 vaccines? Are members of the Portfolio Committee on Health compromised? Constant interrogation of these questions either by citizens or CSOs will help in infusing robust public resource management.

\subsubsection{Vaccine Shortages}

The vaccine rollout trends have been dynamic with ups and downs in respect to vaccine availability across the country. From the 31st of May to the 30th of June Zimbabweans across the country have been failing to access COVID-19 vaccines due to shortages. Many hospitals and clinics mandated to inoculate citizens were turning back those who were coming in for the first jab. This is because there was a shortage and the available vaccines were reserved for those who were coming for the second jab. Hospitals or clinics which had no vaccines for the first jab across the country include but are not limited to Phakama (Gwanda) Nyameni clinic (Marondera), Nyamhunga Clinic, Kariba Heights and Mahombekombe (Kariba) Entumbane Clinic, Luveve, Pumula Clinic (Bulawayo), Glen View Satelite Clinic, Budiriro 1 clinic (Harare), Chiredzi and Chipinge General Hospitals.

Table 2. Vaccines Received and Expected in Zimbabwe before the End of August

\begin{tabular}{|c|c|c|c|c|c|c|}
\hline & & & \multicolumn{2}{|c|}{ TYPE } & \multicolumn{2}{|c|}{ STATUS } \\
\hline Name & Country & Quantity & Purchased & Donation & Received & Pending \\
\hline Sinopharm & China & 400,000 & & $\checkmark$ & $\checkmark$ & \\
\hline Sinovac & China & $1,200,000$ & $\checkmark$ & & $\checkmark$ & \\
\hline Sinovac & China & $2,000,000$ & $\checkmark$ & & $\checkmark$ & \\
\hline Sinovac & China & $1,000,000$ & $\checkmark$ & & $\checkmark$ & \\
\hline Sputnik V & Russia & 50,000 & & $\checkmark$ & $\checkmark$ & \\
\hline Sputnik V & Russia & 75,000 & & $\checkmark$ & & $\checkmark$ \\
\hline Sinopharm & China & 100,000 & & $\checkmark$ & $\checkmark$ & \\
\hline Sinopharm & China & 500,000 & $\checkmark$ & & $\checkmark$ & \\
\hline Covaxin & India & 35,000 & & $\checkmark$ & $\checkmark$ & \\
\hline Covaxin & India & $1,000,000$ & $\checkmark$ & & & $\checkmark$ \\
\hline $\begin{array}{l}\text { Johnson \& } \\
\text { Johnson }\end{array}$ & USA & $5,000,000$ & $\checkmark$ & & & $\checkmark$ \\
\hline Total & & $11,360,000$ & $10,700,000$ & 660,000 & $5,260,000$ & $6,075,000$ \\
\hline
\end{tabular}


With the emergence of the news of the third wave in Zimbabwe many people got into panic mood which culminated into a vaccine rush. As a result, the coping and adapting capacity of the Zimbabwean Health Sector (ZHS) in respect to vaccine rollout was found wanting as the rollout plan could not match the demand. This can be reinforced by the National Coordinator on Government's Response to COVID-19, Agnes Mahomva who asserted that there was indeed a turndown of those who had come for the first dose across the country due to the ministry's slowness in vaccine rollout not shortage. Mahomva's assertion not only exposes government's incapacitation, but it further shadows the availability of the vaccine for citizens at risk.

As of the 13th of August 2021, Zimbabwe had received a total of 5260000 doses both in the form of donations and purchases. A further 6075000 vaccines are expected which include $5000000 \mathrm{~J} \& \mathrm{~J}$ vaccines from the AU (African Vaccine Acquisition Trust and UNICEF), 1000000 vaccine purchases from India and a 75000 -vaccine donation from Russia which will culminate to a total of 6 075000 vaccines upon receipt the donation (see Table 2).

On the 31 st of January 2021 the government announced that it had set aside US\$100 million for the procurement of 20 million vaccines targeting approximately 10 million people which is $60 \%$ of the population to achieve herd immunity. Therefore, taking into consideration the received and expected deliveries of vaccines Zimbabwe has only managed to acquire $56.8 \%$ of the vaccines required to achieve herd immunity. Although it is a positive stride, the government still need to intensify its vaccine purchase to meet up with the mass vaccine demand that is reflected by shortages across country.

\subsubsection{COVID-19 Vaccine Misinformation}

Zimbabwe's pandemic management has been constantly threatened by vaccine misinformation emanating from various intersecting dynamics such as: religion, politics, and science to mention but a few. The politics misinformation emanates from the realist school of thought underpinned by the hegemonic and struggle for power concept. In this regard, vaccines are regarded as a hoax to swindle African resources and a means to terminate the black people through biological welfare [33]. On the other hand, scientist from various nations have been roped into vaccine diplomacy and misinformation strategies. There has been a silent war between western and eastern powers over vaccine with the EU, USA and UK failing to endorse Chinese and Russian vaccines. On the other hand, China and Russia have been accused of misinformation and media gimmick aimed at discrediting western vaccines [34]. To this end, the consequences of vaccine misinformation has an impact on Zimbabwean pandemic management due to globalisation. While religious leaders are also telling their congregants that vaccines are a conduit pipe for the "New World Order" and the famous "mark of the beast" mentioned in the bible in the book of Revelation. This view had detrimental effects on vaccine uptake by Christians who subscribed to this doctrine. A good example is that of Prophet Makandiwa who is alleged to have preached against the vaccines and even declared that he was willing to go to jail than to be vaccinated [35]. The ramifications of his utterance were injurious as UFIC has a huge following. However, the Prophet later made an astonishing change of doctrine in respect to vaccines and urged his members to get vaccines as argued that the COVID-19 vaccine was not the mark of the beast associated with the great tribulation. A move that many believed would help in clearing the religious myths surrounding COVID-19 vaccines.

Even so, vaccine uptake has remained low as the apostolic sector does not believe in the use of medicine. They are of the view that God is the author of their healing thus going to hospital in search of healing was a sin. The impact of this doctrine is reflected by the report on "COVID-19 Admissions and Community Deaths by Vaccination Status" by Dr Agnes Mahomva which was released on the 23rd of July. Figure 1 shows COVID-19 fatality rate by vaccination.

The data presented in Figure 1 shows that 9 in 10 people (88.9\%) of the 207 deaths were not vaccinated, while $3.4 \%$ had received 1 dose and $4.8 \%$ had received 2 doses. This stands as evidence the vaccine is working effectively in reducing mortality rate. However, Zimbabwean pandemic management still faces a low intake from religious people. In trying to rectify this dilemma, the government on the 11th of August declared that if churches want to open they should see to it that their members have been vaccinated.

with members who are unvaccinated, the members together with their leader shall be arrested. Thus the government resorted to the carrot and stick approach in order to influence vaccine intake. This is despite the fact that the government never consulted religious leaders before they make the declaration. 


\title{
COVID-19 Third Wave Mortality: Community Deaths by Vaccination Status as of 22 July 2021 Harare
}

\author{
207 Total Number of deaths analysed (Mortuary data) \\ - $88.9 \%$ NOT vaccinated \\ - $3.4 \%$ Had received 1 dose \\ - $4.8 \%$ Had received 2 doses \\ - $2.9 \%$ Not Known \\ Source: Prof R Makunike-Mutasa University of Zimbabwe Histopathology Department and \\ Member COVID-19 Experts Advisory Committee
}

Figure 1. COVID-19 Fatality Rate by Vaccination

\subsubsection{Vaccine Cheating}

Vaccine cheating and avoidance proliferated due to vaccine misinformation. The vaccine mythical dynamics ranging from religion, politics and science presented in section 5.8 above accounts for vaccine avoidance and cheating. The failure to accept vaccines by citizens and the need to travel without restrictions has led many into purchasing COVID-19 testing certificates and vaccination cards. Investigations conducted in Mutare by Manica Post noted that, some medical officials were now resorting into selling fake COVID-19 certificates and Vaccination. The same was also experienced in Zvishavane were vaccine certificates were being sold on streets. This has negative bearing on pandemic management as it exposes everyone who encounters the bearer of a fake COVID-19 certificate and vaccination card.

\subsubsection{Enhancing Vaccine Intake through Quality Information}

Nature has a way of filling up vacuums, the proliferation of vaccine misinformation in Zimbabwe can be linked to the unavailability of authentic and quality information. For an effective pandemic management there is need to fight vaccine misinformation through effective radio and TV campaign. This will guarantee the dissemination of quality information that will enhance vaccine intake. Vaccine adverts and campaigns should be in all the 16 languages that are constitutional recognized. However, ZIMCODD is concerned with some areas in Chipinge District such as Mabeye (Ward 28) where only netone network is accessible after climbing the mountains. The situation is aggravated by Chizenge and Tsetse control in Mahenye (Ward 30) as well as Maregere, Chisuma and Makoho (Ward 29) where no Zimbabwe mobile network or radio network is accessible. The aforementioned communities rely on Mcell Mozambique for communication and the nearest clinic is approximately $17 \mathrm{kms}$ away.

\subsection{Zimbabwe`s Performance Against Other African Nations}

On the African continent, Zimbabwe has performed well in the vaccine roll out plan. Although the country is experiencing some challenges in the vaccine procurement and redistribution processes she has a better standing compared to the Malawian scenario with only 540 [36] doses left for a population of $19,605,750$ as of the 24th of June 2021. Zimbabwe's performance can be rated by comparing her regional counterparts and Africa at large. The survey conducted by Statista on COVID19 vaccination rate in Africa shows that Zimbabwe was performing relatively well. The survey was carried out in 48 countries, sort to determine which countries were responding effectively to the pandemic through vaccinations. Despite Zimbabwe`s challenges in vaccine distribution and roll out, she came out 8th position in Africa and 3rd in the Southern Africa region. This survey is also reinforced by the WHO which ranked Zimbabwe the 7 th best African country in managing the pandemic [37]. This is evidenced by the presentation in Fig 2 which shows the number of administered COVID-19 vaccine doses per 100 people in Africa. However, complacence should be avoided by acknowledging that there is room for improvement in vaccine acquisition and roll out 
management. Zimbabwe can improve by re-orienting its vaccines purchasing stance by obliterating economies of affection and geopolitics.

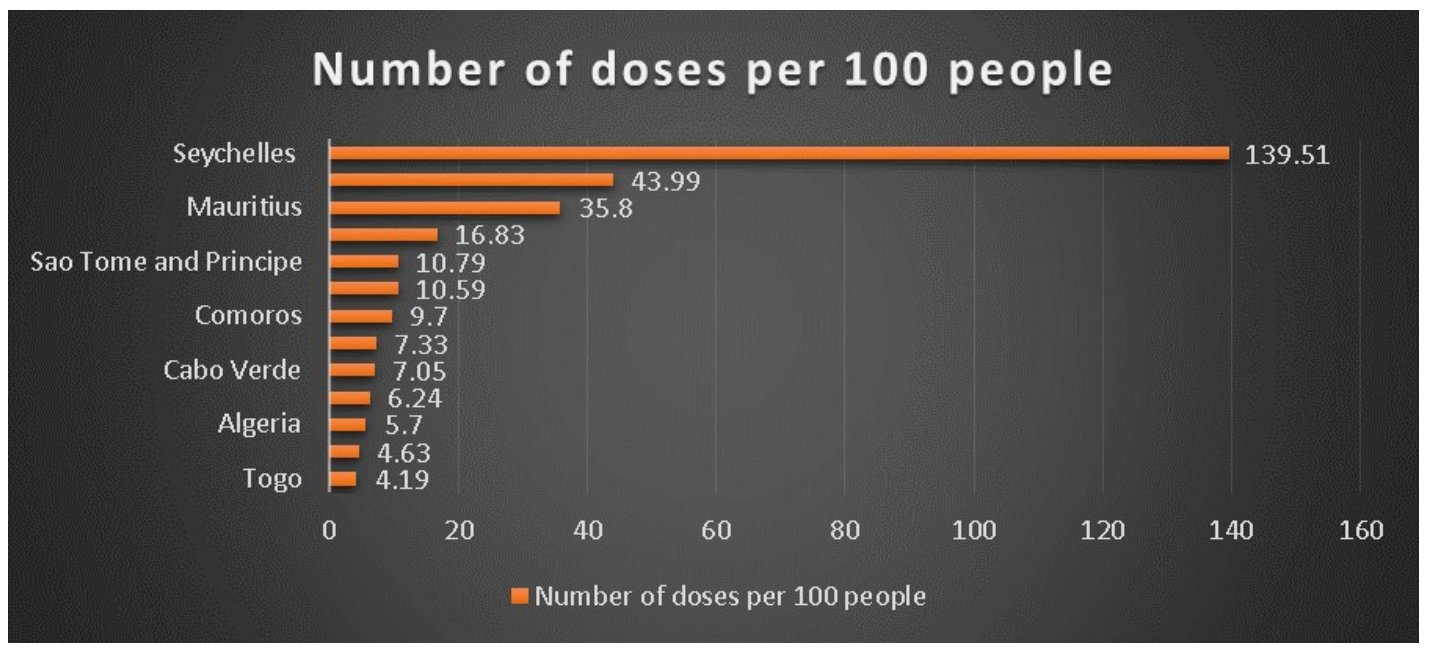

Figure 2. Number of Administered COVID-19 Vaccine Doses per 100 People in Africa [37]

The findings of the survey reflect the entire continent's failure in pandemic management. If one is to consider the vaccine shortages in Zimbabwe and the position she came out it is suffice to say that Africa is lagging behind in vaccination and there is need to gear up.

\section{Conclusion}

The Zimbabwe vaccine programs is on the right course as also evidenced by WHO and Statista ranking which puts it on the 7th and 8th place in Africa respectively. Nevertheless, the vaccine process is marred with anomalies that threaten the gains made with respect to pandemic management. The Zimbabwe Health Sector vaccine distribution which is premised on the adopting and coping capacity of the Zimbabwe health system which is wanting and possesses a great danger to the citizens; this is exacerbated by a lack of transparency and accountability on the administration and purchasing of the vaccine. The government announced that it had reserved US\$100 million for 20 million doses to reach herd immunity. As of 29 July 2021, the government had used US\$93 million towards the purchase of vaccines but the citizens have not yet been furnished with the granular data of the expenditure. Worries are that the so-called donations might be a vehicle of donation-trap diplomacy tailor-made to arm-twist the government to purchase vaccines from China as she stands to gain more than Zimbabwe. In addition, Zimbabwe does not have access to lines of credit and government's lack of transparency makes citizens skeptical about the donations as they fear that it might be a hoax to calm citizens while the donating countries are getting natural resources in return as evidenced by ALROSA which is taking over the Zimbabwe mining industry. Zimbabwe targets to inoculate 10 million people and the acquired vaccines constitute $56.8 \%$ of the target which means the country still has a long way to go and should not bask in the glory of the WHO and Statista rankings. The WHO and Statista rankings are based on the poor performance of other Africa states meaning that the Zimbabwe's thrust should be on achieving herd immunity and not bask in the glory of the rankings. At the same time, vaccine misinformation has remained problematic causing many people to view vaccines as diabolic henceforth finding alternative ways of avoiding and cheating vaccinations.

An examination of the dynamics and trends in vaccine procurement and distribution in Zimbabwe raises several questions that probe for answers and further reflection:

- Has Zimbabwe fallen victim to vaccine donation trap or is it an active participant with benefitting enablers?

- Why did it take long for the government to accept the J\&J vaccine when it's advantages surpass those Sinovac, Sinopharm, Stuptnik V and Covaxin? 
- Could it be that Covid-19 donations were used to lure government to purchase more vaccines from the donating countries?

- Is government taking due diligence and satisfying all public procurement procedures provided for in the Public Procurement and Disposal of Public Assets Act?

- Given the Cyclone Idai Special Audit report and the Special COVID-19 Audit Report, what dictates of public procurement in emergency and disaster situations? Do we have watertight legislative frameworks to guide procedure in emergency situations while equally safeguarding public resources?

- What is the cause of vaccine misinformation and how can the government address such?

- Is the government's perquisite of vaccination for churches to open sufficient to intensify vaccine uptake?

- Should religious leaders be left to authoritatively speak during disasters even if their views will deter great public participation?

- How can the government enhance information dissemination to demystify misinformation?

- Should Zimbabwe boast of WHO and Statista given the fact that Africa's vaccine intake is generally slow.

- What is the nature of public resource management during the pandemic?

These are key questions that every Zimbabwean national needs to bear in mind and reflect on in as far as the issue of dynamics and trends in vaccine procurement and distribution is concerned.

\section{References}

[1] B, Mutizwa, "COVID-19 a Global Nightmare: Revamping the Zimbabwean Health Sector (ZHS) for Future Epidemic and Pandemic Management," Journal of African Problems and Solutions, vol. 2, no. 1, pp. 59-73, 2020.

[2] S. R. T. M. Chilunjika, B. Mutizwa, A. Chilunjika, "Unpacking the Impact of the COVID-19 Pandemic in Zimbabwe`s Public Sector," Journal of Humanities and Social Sciences, vol. 2, no. 3, pp. 93-104, 2020.

[3] S. Chidhau, B. Mutizwa, T. R. Muzama, "The Impact of the Digital Health Interventions in Curbing COVID-19 in Zimbabwe," International Journal of Clinical Inventions and Medical Sciences, vol. 3, no. 1, pp. 40-52, 2021.

[4] Xinhua, "Zimbabwe Receives 3rd Shipment of COVID-19 vaccines from China," Xinhua, p. March 302021.

[5] M, Chingwere, "Chinese Doctors to Help Administer COVID-19 Vaccine", the Herald, February 16, 2021

[6] ZIMCODD, the Bane of Resource-Backed Loans in Zimbabwe Implications for Debt Sustainability. Zimbabwe: zimcodd.org. 2021

[7] Anonymous, "Zimbabwe Reports First Cases of Coronavirus Variant from India" Reuters for Africa, p. 1. May 19, 2021.

[8] Anonymous, Zimbabwe COVID-19 on SitRep 30/05/2021. Zimbabwe: Ministry of HealthZW, 2021.

[9] Anonymous, Zimbabwe COVID-19 on SitRep 14/07/2021. Zimbabwe: Ministry of HealthZW, 2021.

[10] NewsdzeZimbabwe, "Ed Set To Receive Chinese Covid-19 Vaccines," Newsdze Zimbabwe, p. 1, February 14, 2021.

[11] Xinhua, "Zimbabwe's Second Largest City Runs out of COVID-19 Vaccines," Xinhua, May 27, 2021.

[12] C, Mavhunga, "Zimbabweans Protest COVID-19 Vaccine Shortages," Voice of Africa, June 2, 2021.

[13] Xinhua, "Zimbabwe's Second Largest City Runs out of COVID-19 Vaccines," Xinhua, p. 1. May 5, 2021.

[14] S, Mazingaizo, "Vaccine Tourism South Africans Cross Border to Zimbabwe for COVID-19 Jab," Sowetanlive, May 8, 2021.

[15] L. Hernandez, "Strengths and Challenges of Distance Learning Modalities in the New Normal: Basis for Intervention Program," Journal of Humanities and Social Sciences, vol. 3, no. 2, pp. 80-87, 2021. 
[16] M, Doucleff, "Poor Countries Fall Behind in Race to Reserve COVID-19 Vaccines. The Coronavirus Crisis," NPR, November 5, 2021.

[17] A. Capri, "Commentary: How COVID-19 vaccines Are Being Weaponised as Countries Jostle for Influence," Commentary, April 82021

[18] Euronews "EU slams Russia and China for Western Vaccines Disinformation Campaig," Euronews, April 29, 2021.

[19] S, Zhao, "Why China`s Vaccine Diplomacy is Winning," Economics, Politics and Public Policy in East Asia and the Pacific, April 29, 2021.

[20] Xinhua "Zimbabwean president lauds China for donating vaccines" Xinhua, March 22021

[21] M, Chingere, "President Receives Sputunik V Jabs," Herald, June 12, 2021.

[22] T, Muremekedzeyi, "China donates 200,000 more doses of vaccine to Zimbabwe", China Daily, February 26, 2021.

[23] L, Nyamudzanga, "What do we know about resource-backed loans?" The Zimbabwe Independent, March 5, 2021.

[24] Reuters, "Covid-19: Zimbabwe Gets Vaccine Offers from Russia, China as Cases Surge," News24, January 25, 2021.

[25] N. Adhikari, A. Sharma, and J. Nath, "India and the World after Covid-19: Climate Aspect", Journal of Engineering, Technology, and Applied Science, vol. 2, no. 2, pp. 103-109, Aug. 2020.

[26] S, Arrowsmith, Public procurement: Basic concepts and the coverage of procurement rules, in Public procurement relations: an introduction. EU Asia Inter University Network, 2010

[27] M, Terry, "UPDATED Comparing COVID-19 Vaccines: Timelines, Types and Prices," BioSpace, June 20, 2021.

[28] M, Mangwaya, "IMF Rules Out Zimbabwe Bailout" Newsday, June 18, 2021.

[29] Anonymous, "Zimbabwe ALROSA to Hold 70\% in Diamond Venture," FurtherAfrica, July 21, 2019.

[30] P. S. Omoyefa, "Public Sector Reform in Africa: A Philosophical Rethinking," Africa Development, vol. 32, no. 4, pp. 15-30, 2008.

[31] Anonymous, Covid-19. Zimbabwe: Parliament of Zimbabwe, 2021.

[32] N. Ndoro, "US\$89m Covid-19 Funds May Have Been Stolen, Chiwenga Tried To Conceal Report," Nehanda Radio, April 7, 2021.

[33] R. Graham, "Every Effort Must Be Made to Convince Black People of a COVID-19 Vaccine's efficacy and safety," Globe Opinion: Opinion, p. 1, December 1, 2020.

[34] R, Emmott, "Russia, China Show Disinformation to Undermine Trust in Western vaccines: EU", Reuters, April 28, 2021.

[35] T, E, Ndoro, "Prophet Makandiwa Divides Zimbabweans After "Contradicting" Himself on Covid-19 Vaccine", Iharare, July 2021.

[36] L, Chutel, "EXPLAINER | Malawi has Less than 600 Covid-19 vaccine Doses Left: Here's How it Got to this Point," News 24, June 24, 2021.

[37] M, Selah, "COVID-19 Vaccination Rate in Africa 2021, by country" Health, Pharma \& Medtech State of Health, Statista, August 23, 2021. 